\title{
The Bacteriological Profile of Surgical Site Infections in Orthopaedic Implant Surgeries in South-East Nigeria
}

\author{
Kelechukwu A. Okoro1, Osita Ede', Emmanuel C. Iyidobi'1, Ugochukwu U. Enweani², \\ Cajetan U. Nwadinigwe1, Gabriel 0. Eyichukwu' ${ }^{1}$, Udo E. Anyaehie', Francis N. Ahaotu ${ }^{1}$, \\ Richard C. Ezeh ${ }^{1}$
}

${ }^{1}$ Department of Orthopaedics and Trauma, National Orthopaedic Hospital, Enugu, Nigeria

${ }^{2}$ City Clinics, Enugu, Nigeria

Email: edeosita@yahoo.com

How to cite this paper: Okoro, K.A., Ede, O., Iyidobi, E.C., Enweani, U.U., Nwadinigwe, C.U., Eyichukwu, G.O., Anyaehie, U.E., Ahaotu, F.N. and Ezeh, R.C. (2019) The Bacteriological Profile of Surgical Site Infections in Orthopaedic Implant Surgeries in South-East Nigeria. Journal of Biosciences and Medicines, 7, 19-27.

https://doi.org/10.4236/jbm.2019.79003

Received: August 5, 2019

Accepted: August 27, 2019

Published: August 30, 2019

Copyright $\odot 2019$ by author(s) and Scientific Research Publishing Inc. This work is licensed under the Creative Commons Attribution International License (CC BY 4.0).

http://creativecommons.org/licenses/by/4.0/

\begin{abstract}
Background: Knowledge of the common bacteria that cause surgical site infection (SSI) and their antibiotic sensitivity is mandatory if treatment of surgical infection is to be successful. The threat of the emergence of resistant strains of bacteria is ever-present. Hence, a sensitivity directed therapy is paramount for the successful eradication of organisms with minimal risk of development of antibiotic resistance. Aim: The aim is to identify the common bacteria that cause SSI in orthopaedic implant surgeries in our hospital. Method: This is a prospective longitudinal study that includes all orthopaedic surgeries involving the use of implants within one year. Patients that had major orthopaedic surgeries involving implant were followed up and their wounds inspected for signs of SSI on postoperative days 3, 7, 14, 42 and 90. Wound swab was taken for microscopy, culture and sensitivity analysis from those who had wound infection, based on the CDC guidelines. Results: One-hundred and sixteen patients met our inclusion criteria and were included in the analysis. There were 62 males and 54 females. The mean age of the participant was 39.62 years ( $S D=15.02$ years). Fracture fixation with plates and screws was the most common implant surgery done. The incidence of SSI was 2.6\%, and Escherichia coli was the most common isolated pathogen. All the SSIs were superficial incisional type, and the infection was monomicrobial in $67 \%$ of cases and polymicrobial in $33 \%$. All of the isolated pathogens were sensitive to Imipenem and Gentamycin. Conclusion: Superficial incisional SSI is the most common type of SSI in this study. Escherichia coli is the most frequent pathogen in SSI affecting implant surgeries in our hospital. Gentamycin and Imipenem should be used for the prophylaxis of SSI in our environment.
\end{abstract}




\section{Keywords}

SSI, Bacteriology, Orthopaedic Implant, Nigeria

\section{Introduction}

Surgical site infections (SSI) are defined as infection occurring along the surgical wound within 30 days after surgery or within one year if an implant is used and left in place [1] [2]. They are categorized as incisional and organ/space infections, with the former further classified as superficial and deep [2]. The former involves the skin and subcutaneous tissue while the latter affects tissues underneath the deep fascia. Organ/Space infection involves organ manipulated or entered during the procedure and would include periprosthetic or peri-implant infections. The CDC has developed guidelines for the diagnosis of both incisional and organ/space infections [2]. Prevention of SSI in orthopaedic implant surgeries is paramount to the surgeon since infections, particularly periprosthetic and peri-implant infections, cause substantial morbidity to the patient.

The worldwide incidence of SSI ranges from as low as $2.6 \%$ to as high as 41.9\% [3]. The National Healthcare Safety Network (NHSN) (USA) data included 16,147 SSIs following 849,659 operative procedures in all groups. They reported an overall rate of $1.9 \%$ from 2006 to 2008 [4]. However, the incidence of reported SSI in Nigeria has been higher than that reported in the USA, with the prevalence ranging from $4.6 \%$ to $16.7 \%$ [5] [6] [7] [8]. Surgical site infections increase overall hospital costs, increase the length of hospital stay, may increase the need for revision surgeries and may cause the death of a patient.

However, complete eradication of the offending pathogen requires a microbiological diagnosis to type the organism and its antimicrobial sensitivity. Blind antibiotic therapy encourages the emergence of resistant strains and may be ineffective if the pathogen is not sensitive to the drug. This may cause a delay in the appropriate treatment of the patient and also wastes the patient's money. In addition to guiding antibiotic therapy, knowledge of the most common pathogens causing SSI may also help to plan containment in the case of outbreaks of nosocomial infections in surgical wards and intensive care units.

The trend of the offending organisms in SSI has changed over time. Historically, Staphylococcus aureus has been the most commonly isolated microorganism in SSI [5] [9]. However, other studies, most of them recent, have demonstrated Escherichia coli as the most predominant bacterium in SSI [10] [11]. Also, emerging organisms like Vancomycin-resistant Enterococci and gram-negative bacilli with unusual patterns of resistance have been isolated more frequently [12]. In orthopaedic SSIs, gram-positive organisms predominate, with both methicillin-resistant and susceptible Staphylococcus aureus being the most common microorganism [7] [13] [14]. This study aims to investigate the most common pathogen responsible for SSI in orthopaedic implant surgery. 


\section{Patients and Methods}

This work was done at the National Orthopaedic Hospital, Enugu, in South-East Nigeria. It is a regional tertiary hospital that caters for specialist Orthopaedics and trauma cases. We received ethical approval from the Hospital's Research and Ethics Committee and written informed consent was obtained from each participant. The inclusion criteria were all patients 18 years and above undergoing clean orthopaedic implant surgeries at the main theatre of the hospital and who gave informed consent to the study. The exclusion criteria include open wounds in any part of the body, immunosuppression such as HIV infection, chronic steroid therapy, malignancy, ongoing sepsis, and refusal of consent.

The required sample size for the study was calculated with the formula for a cross-sectional survey, $n=z^{2} p q / d^{2}$, where $n=$ sample size, $p=$ proportion of variable of interest, $q=1-p$ and $d=$ precision. In the preceding year, 480 clean orthopaedic implant surgeries were done in our hospital, out of a total of 667 major orthopaedic operations. This gives a proportion of clean orthopaedic implant surgery of 0.72 . Setting precision at $10 \%$, and $z$ at 1.96 (95\% confidence level), and substituting into the equation gives a sample size of approximately 78 subjects. Additional eight subjects were added to account for a possible drop-out rate of $10 \%$. Therefore, a minimum sample size of 86 subjects is required at a confidence level of $95 \%$ and a precision of $10 \%$.

Data collection was from November 2017 to October 2018. Every patient for a major orthopaedic surgery involving implant within this period was counselled about the study and assessed for the selection criteria. Eligible patients were scrubbed with $4 \%$ Chlorhexidine gluconate in water, dried and painted with $70 \%$ isopropyl alcohol as per the hospital's protocol. The surgery was done by a Consultant Orthopaedic Surgeon or a senior registrar under the supervision of a Consultant. The operations done are shown in Table 1.

Standard perioperative protocols were observed for all patients. These include administration of 1gram of intravenous Ceftriaxone at the induction of anaesthesia if general anaesthesia was used, or during the preloading, if a neuraxial blockade (spinal or epidural) was used. If a tourniquet was used, the tourniquet was applied 10 minutes after giving the antibiotics. Skin scrubbing was done for five minutes, and if there was a breach in aseptic technique intraoperatively, the patient was excluded from subsequent analysis. Two further courses of Ceftriaxone were given postoperatively. If a drain was used, it was removed at 48 hours except if the drainage exceeded $50 \mathrm{mls}$ the previous day. The urethral catheter was removed 24-hours after surgery.

The wound was inspected on postoperative days 3, 7, 14, 42 and 90. We specifically look for features of SSI in line with CDC NNIS definitions of SSI-purulent discharge, tenderness, localised swelling, redness or local warmth, positive culture from aseptically collected fluid or tissue from the surgical track [2]. When surgical site infection was diagnosed clinically, wound swab was aseptically taken from the infected surgical site and transported to the microbiology 
Table 1. The surgeries that were done during the study period.

\begin{tabular}{ccc}
\hline Type of Surgery & $\mathbf{n}$ & (\%) \\
\hline ORIF with plates and screws & 47 & 40.5 \\
ORIF with intramedullary interlocking nails & 38 & 32.8 \\
Corrective osteotomy & 17 & 14.7 \\
Posterior spinal decompression and pedicle screw fixation & 4 & 3.4 \\
Total knee replacement & 5 & 4.3 \\
Total hip replacement & 3 & 2.6 \\
Osteoclasis and intramedullary interlocking nailing & 2 & 1.7 \\
\hline
\end{tabular}

laboratory for microscopy, culture and sensitivity. The culture media used were Chocolate agar and MacConkey medium, and the culture was for a minimum of 72 hours and was done at a temperature of $37^{\circ} \mathrm{C}$.

An antibiotic sensitivity test was done on a nutrient agar to which an inoculum of bacterial colony growth was applied. The gram-positive and gram-negative antibiotic disks were sequentially applied to the nutrient agar for 24 hours. A zone of lysis indicates that the colony is sensitive to the antibiotic represented by that particular zone.

\section{Results}

One-hundred and sixteen patients met our inclusion criteria and were included in the final analysis. There were 62 males (53.4\%) and 54 females (46.6\%). The mean age of the participant was 39.62 years ( $S D=15.02$ years). Surgical site infection occurred in three cases $(2.6 \%)$ in this study. The infections were all superficial incisional SSI and were characterized by purulent wound drainage. They were observed on the $6^{\text {th }}, 8^{\text {th }}$ and $9^{\text {th }}$ postoperative days. All healed with daily wound dressing and antibiotics based on the sensitivity analysis.

Escherichia coli was isolated in two cases (67\%) of SSI while mixed isolates of Escherichia coli, Klebsiella spp. and Staphylococcus aureus were found in the third case (33\%) of SSI. All the bacterial strains were sensitive to Gentamicin and Imipenem antibiotics. The microbial isolates with the antibiogram are shown in Table 2.

\section{Discussions}

Our study has identified Escherichia coli as the most common cause of SSI in orthopaedic implant surgery. This is a departure from earlier studies that have consistently shown Staph aureus as the culprit in most cases [15] [16] [17] [18] [19]. It is noteworthy that ten years ago, Staphylococcus aureus was the most common cause of implant-associated infection in our hospital [7]. The emergence of gram-negative bacteria may be due to the preferential use of Amoxicillin-Clavulanic acid as the first-choice prophylactic antibiotic within the last few 
years. This is because the drug has more activity against the gram-positive Staph aureus, which hitherto, has been the most common agent causing SSI.

Many landmark works have also identified Staph aureus as the most common pathogen in SSI. The National Nosocomial Infections Surveillance System (NNISS) published the common causes of SSI between the year 1986 to 1996 [20], see Table 3. Also, a 2009 study of SSI in Orthopaedic implant surgeries have identified Staph aureus as the most common cause of SSI [17], Table 4.

Table 2. The bacterial isolates with their antibiotic sensitivities.

\begin{tabular}{cccccccccccc}
\hline Bacteria & $\begin{array}{c}\text { Total } \\
\text { number of } \\
\text { isolates }\end{array}$ & IPM & GT & CAZ & CXM & CRO & LEV & OFX & CIP & PEF & AMC \\
\hline $\begin{array}{c}\text { Escherichia coli } \\
\text { Klebsiella spp. }\end{array}$ & 3 & Yes & Yes & No & No & Yes & No & No & Yes & No & No \\
$\begin{array}{c}\text { Staphylococcus } \\
\text { aureus }\end{array}$ & 1 & Yes & Yes & No & Yes & No & Yes & No & No & No & No \\
& & Yes & Yes & No & No & No & Yes & No & Yes & No & No \\
\hline
\end{tabular}

$\mathrm{IPM}=$ Imipenem, $\mathrm{GT}=$ Gentamicin, $\mathrm{CAZ}=$ Ceftazidime $. \mathrm{CXM}=$ Cefuroxime, $\mathrm{CRO}=$ Ceftriaxone, $\mathrm{LEV}=$ Levofloxacin, OFX = Ofloxacin, CIP = Ciprofloxacin, $\mathrm{PEF}=$ Pefloxacin, AMC = Amoxicillin-Clavulanic acid.

Table 3. Distribution of pathogens isolated from SSIs, National Nosocomial Infections Surveillance System, 1986 to 1996 [20].

\begin{tabular}{ccc}
\hline Pathogen & $\begin{array}{c}\text { Percentage of Isolates } \\
1986-1989 \\
(\mathbf{N}=16,727)\end{array}$ & $\begin{array}{c}\text { Percentage of Isolates } \\
1990-1996 \\
(\mathbf{N}=17,671)\end{array}$ \\
\hline $\begin{array}{c}\text { Staphylococcus aureus } \\
\text { Coagulase-negative } \\
\text { Staphylococci }\end{array}$ & 17 & 20 \\
Enterococcus spp. & 12 & 14 \\
Escherichia coli & 13 & 12 \\
Pseudomonas aeruginosa & 10 & 8 \\
Enterobacter spp. & 8 & 7 \\
Proteus mirabilis & 8 & 3 \\
Klebsiella pneumoniae & 4 & 3 \\
Other Streptococcus spp. & 3 & 3 \\
Candida albicans & 3 & 3 \\
Group D streptococci \\
(non-enterococci)
\end{tabular}

* Pathogens representing less than $2 \%$ of isolates are excluded. 
Table 4. Distribution of pathogens in orthopaedic implant SSIs [17].

\begin{tabular}{cc}
\hline Bacteria & No. $(\%)$ \\
\hline S. aureus & $34(21.94)$ \\
Klebsiella ozaenae & $26(16.77)$ \\
P. aeruginosa & $24(15.50)$ \\
E. coli & $23(14.83)$ \\
S. epidermidis & $14(9.05)$ \\
Enterobacter cloacae & $11(7.10)$ \\
P. mirabilis & $9(5.80)$ \\
Acinetobacter baumannii & $7(4.51)$ \\
Streptococcus viridans & $3(1.93)$ \\
Bacteroides & $3(1.93)$ \\
Enterococcus faecalis & $1(0.64)$
\end{tabular}

Our finding is in agreement with the study by Young-Dede [21], which reported gram-negative bacteria as the most common organism; although his study included non-implant cases. In another prospective study involving clean orthopaedic implant surgeries, Suneet et al. [22] found that gram-negative Enterobacteriaceae accounted for $62.79 \%$ of isolated organisms, with Klebsiella and Escherichia coli dominating at $39.53 \%$ and $18.6 \%$ respectively. Agrawal et al. [23] and Lalremruata et al. [24] observed similar findings with Gram-negative bacteria accounting for $74.8 \%$ and $66.94 \%$ of the total number of isolates. Also, Olufunmilola [11] reported Escherichia coli as the predominant pathogen in orthopaedic SSIs.

In this study, the antimicrobial susceptibility test revealed that Escherichia coli, Klebsiella spp. and Staphylococcus aureus were uniformly sensitive to Imipenem and Gentamycin. This finding is similar to an earlier study by Khosravi [17] and Kumar [19], which reported Imipenem as the most effective antibiotic against the isolated bacteria. In the same vein, the sensitivity of the isolates to Gentamycin was documented by Kumar [19]. In addition to the drugs as mentioned earlier, Klebsiella was found to be susceptible to Levofloxacin and Cefuroxime while Staphylococcus aureus was observed to be sensitive to Levofloxacin and Ciprofloxacin. All the isolated bacteria were uniformly resistant to Amoxicillin/Clavulanic acid. Amoxicillin/Clavulanic acid has been traditionally prescribed postoperatively in the study centre over the years, which may account for the uniform resistance of these isolates to it.

\section{Conclusion and Recommendation}

The trend of the aetiology of SSI associated with implant surgeries in our environment has changed. Escherichia coli is presently the most common cause of implant-associated SSI. There is a high level of resistance to Amoxicillin-Clavulanic acid among the isolates, and this should no longer be used as a 
prophylaxis for SSI in implant surgeries. Gentamycin and Imipenem should be used for the prophylaxis of SSI in our environment.

\section{Limitations of the Study}

Non-bacterial pathogens and mycobacteria were not studied.

\section{Financial Support}

We received a research grant from the hospital management for this work

\section{Conflicts of Interest}

The authors declare no conflicts of interest regarding the publication of this paper.

\section{References}

[1] Daniel, A.A. and Dellinger, E.P. (2012) Surgical Infections and Choice of Antibiotics. In: Townsend Jr., C.M. and Beauchamp, R.D., Eds., Sabiston Textbook of Surgery: The Biological Basis of Modern Surgical Practice, 18th Edition, Saunders, Philadelphia, 299-327.

[2] Horan, T.C., Gaynes, R.P., Martone, W.J., Jarvis, W.R. and Emori, T.G. (1992) CDC Definitions of Nosocomial Surgical Site Infections, 1992: A Modification of CDC Definitions of Surgical Wound Infections. Infection Control \& Hospital Epidemiology, 13, 606-608. https://doi.org/10.1017/S0195941700015241

[3] Davenport, M. and Doig, C.M. (1993) Wound Infection in Pediatric Surgery: A Study in 1,094 Neonates. Journal of Pediatric Surgery, 28, 26-30. https://doi.org/10.1016/S0022-3468(05)80348-3

[4] Mu, Y., Edwards, J.R., Horan, T.C., Berrios-Torres, S.I. and Fridkin, S.K. (2011) Improving Risk-Adjusted Measures of Surgical Site Infection for the National Healthcare Safety Network. Infection Control Hospital Epidemiology, 32, 970-986. https://doi.org/10.1086/662016

[5] Enweani, U.N. (1991) Surgical Wound Sepsis in Clean Orthopaedic Procedures: Bacteriology and Sensitivity in a Regional Specialist Centre. Orient Journal of Medicine, 3, 3-6.

[6] Albert, F.P., van Laarhoven, C.J.H.M. and David, B.C. (2010) The Incidence of Surgical Site Infection Following Adult Spinal Deformity Surgery: An Analysis of Patient Risk. European Spine Journal, 19, 982-988.

https://doi.org/10.1007/s00586-009-1269-1

[7] Ikeanyi, U.O.E. (2007) Postoperative Wound Infections in Clean Cases-Incidence, Risk Factors and Bacteriology at the National Orthopaedic Hospital Igbobi, Lagos. A Dissertation Submitted to the National Postgraduate Medical College of Nigeria, Lagos.

[8] Mbamali, E.I. (1981) Internal Fixation of Femoral Shaft Fractures at the Ahmadu Bello University Teaching Hospital, Zaria. Nigerian Medical Practitioner, 2, 81-85.

[9] Mangram, A.J., Horan, T.C., Pearson, M.L., Silver, L.C. and Jarvis, W.R. (1999) Guideline for Prevention of Surgical Site Infection, 1999. Hospital Infection Control Practices Advisory Committee. Infection Control \& Hospital Epidemiology, 20, 250-278. https://doi.org/10.1086/501620 
[10] Shahane, V., Bhawal, S. and Lele, U. (2012) Surgical Site Infections: A One-Year Prospective Study in a Tertiary Care Centre. International Journal of Health Sciences, 6, 79-84. https://doi.org/10.12816/0005976

[11] Olufunmilola, B.M., Olugbenga, A.O. and Folasoge, A.A. (2013) Bacterial Agents of Surgical Site Infections in South-Western Nigeria. American Journal of Biomedical Sciences, 5, 217-225. https://doi.org/10.5099/aj130400217

[12] Culver, D.H., Horan, T.C., Gaynes, R.P., Martone, W.J., Jarvis, W.R., et al. (1991) Surgical Wound Infection Rates by Wound Class, Operative Procedure, and Patient Risk Index. National Nosocomial Infections Surveillance System. The American Journal of Medicine, 91, 152S-1527S. https://doi.org/10.1016/0002-9343(91)90361-Z

[13] Ravikant, D., Arunesh, S., Pranay, S., Sagarika, P. and Ramnesh, M. (2015) Microbial Profile and Antibiotic Susceptibility Pattern of Surgical Site Infections in Orthopaedic Patients at a Tertiary Hospital in Bilaspur. International Journal of Scientific Study, 3, 43-47.

[14] Greene, LR. (2012) Guide to the Elimination of Orthopedic Surgery Surgical Site Infections: An Executive Summary of the Association for Professionals in Infection Control and Epidemiology Elimination Guide. American Journal of Infection Control, 40, 384-386. https://doi.org/10.1016/j.ajic.2011.05.011

[15] Onche, I. and Adedeji, O. (2004) Microbiology of Post-Operative Wound Infection in Implant Surgery. Nigerian Journal of Surgical Research, 6, 37-40. https://doi.org/10.4314/njsr.v6i1-2.54787

[16] Madu, K.A. (2008) Post-Operative Wound Infection in Implant Surgery at the National Orthopaedic Hospital Enugu. A Dissertation Submitted to the National Postgraduate Medical College of Nigeria, Lagos.

[17] Khosravi, A.D., Ahmadi, F., Salmanzadeh, S., Dashtbozorg, A. and Abasi, M.E. (2009) Study of Bacteria Isolated from Orthopaedic Implant Infections and Their Antimicrobial Susceptibility Pattern. Research Journal of Microbiology, 4, 158-163. https://doi.org/10.3923/jm.2009.158.163

[18] Ogugua, J.H. (2014) Surgical Site Infection in Implant Surgery. A Dissertation Submitted to the National Postgraduate Medical College of Nigeria, Lagos, 35-62.

[19] Kumar, S., Sengupta, M., Hada, V., Sarkar, S. and Bhatta, R. (2017) Early Postoperative Wound Infection in Patients Undergoing Orthopaedic Surgery with an Implant. International Journal of Scientific Study, 5, 44-48.

[20] Centres for Disease Control and Prevention (1996) National Nosocomial Infections Surveillance (NNIS) Report, Data Summary from October 1986-April, 1996. A Report from the National Nosocomial Infections Surveillance (NNIS) System. American Journal of Infection Control, 24, 380-388.

https://doi.org/10.1016/S0196-6553(96)90026-7

[21] Young-Dede, E. (2001) Single versus Multiple-Dose Antibiotic Prophylaxis in Surgery: A Comparative Study. A Dissertation Submitted to the National Postgraduate Medical College of Nigeria, Lagos, 26-41.

[22] Suneet, T., Abhishek, P., Santosh, K.M. and Mayank, V. (2015) Incidence and Risk Factors for Early Surgical Site Infection in Elective Orthopaedic Implant Surgeries: A Prospective Study. Journal of Evolution of Medical and Dental Sciences, 4, 2505-2511.

[23] Agrawal, A.C., Jain, S., Jain, R.K. and Raza, H.K. (2008) Pathogenic Bacteria in an Orthopaedic Hospital in India. The Journal of Infection in Developing Countries, 2, 120-123. https://doi.org/10.3855/T2.2.120 
[24] Lalremruata, R., Krishnaprakash, S., Dhal, A.K. and Sud, A. (2014) Bacterial Pathogens Prevalent amongst Orthopaedic Patients in New Delhi. Journal of the Academy of Clinical Microbiologists, 16, 57-60.

https://doi.org/10.4103/0972-1282.144707 